\title{
A Systematic Review and Meta-Analysis of Palpation Versus Ultrasound-Guided Fine Needle Aspiration of Thyroid Nodules
}

\author{
Jacob Matz BSc, MD', Mohamed Abdolell MSc'2 Jill Hayden DC PhD², Joseph Nasser DDS MD 4 \\ ${ }^{1}$ Class of 2013, Faculty of Medicine, Dalhousie University \\ ${ }^{2}$ Faculty of Medicine, Department of Diagnostic Radiology, Dalhousie University \\ ${ }^{3}$ Faculty of Medicine, Department of Community Health and Epidemiology, Dalhousie University \\ ${ }^{4}$ Faculty of Medicine, Division of Otolaryngology, Dalhousie University
}

\begin{abstract}
Background: Thyroid nodules are a common clinical finding. Fine-needle aspiration (FNA) is the most widely accepted diagnostic tool used to differentiate malignant and benign thyroid nodules. FNA can be carried out by manual palpation of the nodule or with ultrasound guidance. Existing clinical practice guidelines give mixed recommendations regarding the use of ultrasound guidance for thyroid FNA. Given the inconsistencies in the guidelines, we performed a systematic review and meta-analysis to compare the diagnostic accuracy of palpationguided fine needle aspiration (PG-FNA) versus ultrasound-guided fine needle aspiration (USG-FNA).

Methods: Studies comparing PG-FNA and USG-FNA were identified through a search of PubMed, the Cochrane Library, and Embase (1990- December 2011). Titles and abstracts were reviewed and studies were selected for a full text review. Meta-analysis of included studies was performed to estimate the average sensitivity, specificity, and rate of inadequate samples for each technique.

Results: We screened 1934 citations and selected seven studies meeting our predefined inclusion criteria. The pooled sensitivity of USG-FNA was found to be higher than PG-FNA $[0.91(\mathrm{Cl}=0.82,1.0)$ and $0.79(\mathrm{Cl}=0.69,0.85)$, respectively]. The pooled specificity of USG-FNA was also found to be slightly higher than PG-FNA $[0.77(\mathrm{Cl}=0.69,0.85)$ and 0.73 $(\mathrm{Cl}=0.64,0.81)$, respectively]. The mean rate of inadequate samples was higher for PG-FNA at $14.7 \%$ versus $8.4 \%$ for US-FNA.
\end{abstract}

Conclusions: Our findings show that USG-FNA has a higher diagnostic accuracy than PG-FNA and a lower rate of inadequate samples. Overall, these findings suggest an advantage to the use of USG-FNA over PG-FNA.

Thyroid nodules are a common clinical finding. The prevalence of thyroid nodules detectable on clinical exam ranges between 4-7\%. ${ }^{1}$ With the use of ultrasound examination, the prevalence of nodules increases dramatically and ranges from $19 \%-60 \% .^{2}$ The vast majority of thyroid nodules are benign. It is therefore important to distinguish which ones are benign from those that are malignant. The malignancy rate of palpable nodules is around $5 \% .{ }^{3}$ Fine-needle aspiration (FNA) biopsy has been the most widely accepted diagnostic tool used to evaluate thyroid nodules due to its accuracy, ease, safety, and cost-effectiveness. ${ }^{4,5}$ The ability of FNA to distinguish benign from malignant nodules has greatly reduced the number of surgeries for nodules that were preoperatively diagnosed as benign. ${ }^{6,7}$

Palpation-guided FNA (PG-FNA) is the traditional method for the evaluation of thyroid nodules. Estimates of the accuracy of the technique vary, with sensitivity ranging between $57-93 \%{ }^{5}$ and specificity ranging between $50-100 \% \%^{5,7-12}$ The rates of false-positive and false-negative findings are reported to be $3 \%$ and $5 \%$, respectively. ${ }^{5,13}$ Studies have reported that up to $40 \%$ of specimens collected using PG-FNA are inadequate, defined as those that did not contain the minimal adequate material for cytological diagnosis. ${ }^{8,14,15}$

Ultrasound-guided FNA (USG-FNA) allows for the visualization of the needle and the nodule during the biopsy. This technique has the potential of reducing the rate of false-negative and non-diagnostic results. Reports of the sensitivity and specificity of the technique vary and range between $66 \%-100 \%$ and $70 \%-96 \%$, respectively. ${ }^{8}$ The reported false negative rate is $1 \%-2 \%{ }^{8}$ The reported rate of inadequate samples is $4 \%-21 \% .{ }^{5,8,9}$ 
Currently, recommendations for the assessment of thyroid nodules vary between organizations. Some organizations promote the universal use of ultrasound guidance while others advocate for a more selective approach. The American Thyroid Association (ATA) recommends USG-FNA for nodules that are difficult to palpate or partially cystic. ${ }^{16}$ The guidelines offered by the US National Cancer Institute ${ }^{17}$ and the British Thyroid Association ${ }^{18}$ state that palpation-guided FNA should only be used when the nodule is discrete, readily palpable and is mostly solid. On the other hand, the American Association of Clinical Endocrinologists (AACE), the Associazione Medici Endocrinologi (AME), and the European Thyroid Association (ETA) consensus guidelines state that FNA biopsy should be carried out under ultrasound guidance to reduce the possibility of false-negative diagnoses and decrease the non-diagnostic rate. ${ }^{19}$ The guidelines suggested by different organizations are therefore inconsistent on this point.

A number of studies have been published in the past two decades addressing the use of PG-FNA and USG-FNA; however, they have not been systematically identified and synthesized. We performed a systematic review and meta-analysis of the existing literature to determine the test accuracy of PG-FNA versus USG-FNA.

\section{Methods}

Literature Search

All studies that compared PG-FNA with USG-FNA were identified through an electronic search of PubMed, the Cochrane Library, and EMBASE databases. Professional librarians assisted in conducting a comprehensive search. The search included studies in the English language that were published between January 1990 and December 2011. The following $\mathrm{MeSH}$ and keyword search terms were used: "thyroid neoplasms", "thyroid cancer", "thyroid nodule", "needle biopsy", "ultrasonography", and "palpation". As part of the search, bibliographies of included studies and relevant other systematic reviews were manually inspected for relevant articles. The scheme for the search is illustrated in Figure 1.

\section{Study Selection}

To be included in our review, studies must have met the following inclusion criteria: had a retrospective or prospective study design comparing USG-FNA versus PG-FNA to diagnose thyroid malignancy; reported the sensitivity, specificity, and inadequacy rate of each diagnostic technique and presented the raw data; used a surgical pathologic specimen as a reference standard

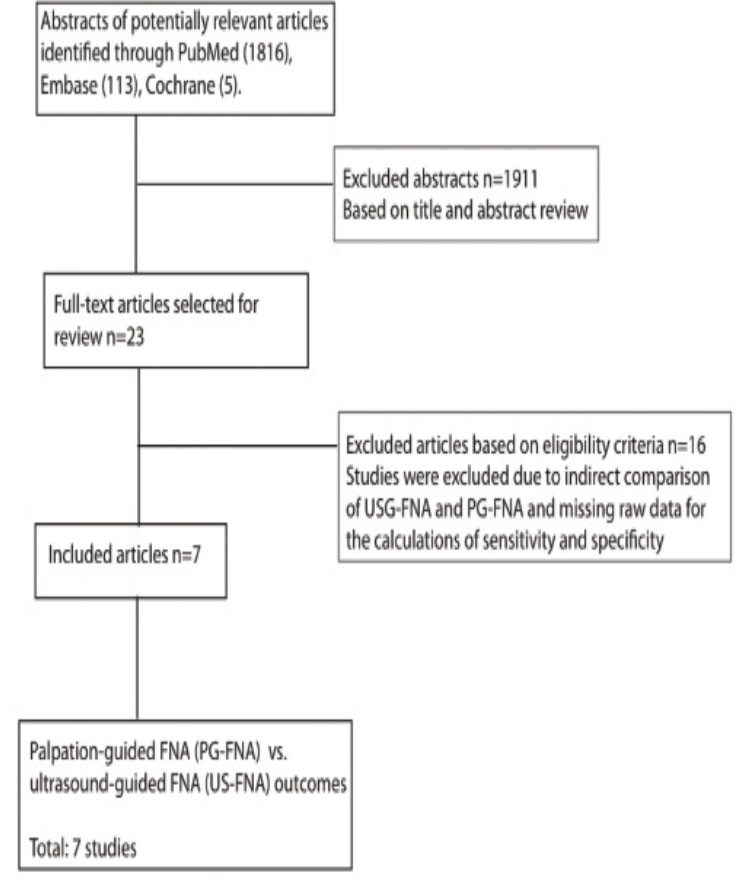

Figure 1. Study selection

and was written in the English language. People of all ages were included in data analysis. Studies that compared the diagnostic techniques in either the same patient population or two different patient populations were included.

Case reports and commentaries were excluded from the analysis. Studies in languages other than English were excluded.

Two reviewers independently read all titles and abstracts and selected articles for a full text review. Full text articles were then read independently. The co-authors (J.M. and J.N.), reached consensus on studies for inclusion and exclusion. Figure 1 shows the flow chart for the search and article selection. All studies that compared PG-FNA and USG-FNA and conformed to selection criteria were included..$^{5,7-12}$

\section{Data Collection}

Identifying information, such as the authors' names, the journal name, the year of publication as well as raw data for true-positive, true-negative, false-positive, and false-negative values, was extracted from the included studies. Values for sensitivity and specificity were calculated for each study, using the raw data. The calculated values were compared with those reported in the studies. In cases of discrepancy, calculated values were used for the meta-analyses. 
Nodules that were considered benign on cytology were said to be negative. Nodules that were found to be malignant, suspicious, or indeterminate were said to be positive. Inadequate samples, defined as those that did not contain the minimal adequate material for cytological diagnosis, were excluded from the meta-analyses of diagnostic accuracy. These values, however, were used in the analyses exploring the rates of inadequacy. Using the above rules consistently across the studies, true-positives, true-negatives, falsepositives, and false-negatives were used to calculate the sensitivity, specificity, and inadequacy rate for each study. The results were compared with the diagnostic values presented in the studies.

The studies selected for the review varied in their classification of indeterminate nodules. The indeterminate category typically includes nodules with a predominantly follicular pattern or a prevalence of Hurthle cells, where a clear-cut cytological diagnosis cannot be made. Some studies included these nodules as positive findings ${ }^{8}$, some as suspicious ${ }^{5}$, and some as negative. ${ }^{11}$ In our analysis, nodules that were deemed to be indeterminate on cytology were classified as a positive finding. The reason for this categorization is that, in practice, such samples would either be assessed with further diagnostic testing, or depending on the clinical context, would be enough to warrant thyroid surgery.

\section{Quality Assessment}

The QUADAS tool for diagnostic studies was used to evaluate the quality of the selected studies. ${ }^{20}$ The 14 questions used for quality assessment cover elements such as the patient spectrum, the selection criteria, the adequacy of reference standard, and incorporation bias and verification bias (Table 1 ).

\section{Meta-Analysis}

Random effects models were chosen to enable generalization beyond the observed set of studies to make inferences about the parameters of a larger population of studies that may not be strictly identical to the observed set. Pooled estimates of sensitivity and specificity, with confidence intervals generated by random effects models are more appropriately reflective of the true confidence intervals than those generated from fixed effects models.

The meta package ${ }^{21}$ of the $\mathrm{R}$ language for statistical computing was used to perform the meta-analyses. ${ }^{22}$ The $\mathrm{I}^{2}$ statistic was used to measure the percentage of
Table 1: Items for quality assessment

\begin{tabular}{|c|c|}
\hline Item 1 & $\begin{array}{l}\text { Was the spectrum of patients representative of the patients who will } \\
\text { receive the test in practice? }\end{array}$ \\
\hline Item 2 & Were the selection criteria clearly described? \\
\hline Item 3 & Is the reference standard likely to classify the target condition? \\
\hline Item 4 & $\begin{array}{l}\text { Is the time period between the reference standard and the index test short } \\
\text { enough to be reasonably } \\
\text { sure that the target condition did not change between the two tests? } \\
\text { Did the whole sample or a random selection of the sample, receive }\end{array}$ \\
\hline Item 5 & $\begin{array}{l}\text { verification } \\
\text { using a reference standard of diagnosis? }\end{array}$ \\
\hline Item 6 & $\begin{array}{l}\text { Did patients receive the same reference standard regardless of the index test } \\
\text { result? }\end{array}$ \\
\hline Item 7 & $\begin{array}{l}\text { Was the reference standard independent of the index test } \\
\text { (i.e. the index test did not form part of the reference standard)? }\end{array}$ \\
\hline Item 8 & $\begin{array}{l}\text { Was the execution of the index test described in sufficient detail to permit } \\
\text { replication of the test? }\end{array}$ \\
\hline Item 9 & $\begin{array}{l}\text { Was the execution of the reference standard described in sufficient detail to } \\
\text { permit its replication? }\end{array}$ \\
\hline Item 10 & $\begin{array}{l}\text { Were the index test results interpreted without knowledge of the results of } \\
\text { the reference standard? }\end{array}$ \\
\hline Item 11 & $\begin{array}{l}\text { Were the reference standard results interpreted without knowledge of the } \\
\text { results of the index test? }\end{array}$ \\
\hline Item 12 & $\begin{array}{l}\text { Were the same clinical data available when test results were interpreted as } \\
\text { would be available when the test is used in practice? }\end{array}$ \\
\hline Item 13 & Were uninterpretable/ intermediate test results reported? \\
\hline Item 14 & Were withdrawals from the study explained? \\
\hline
\end{tabular}

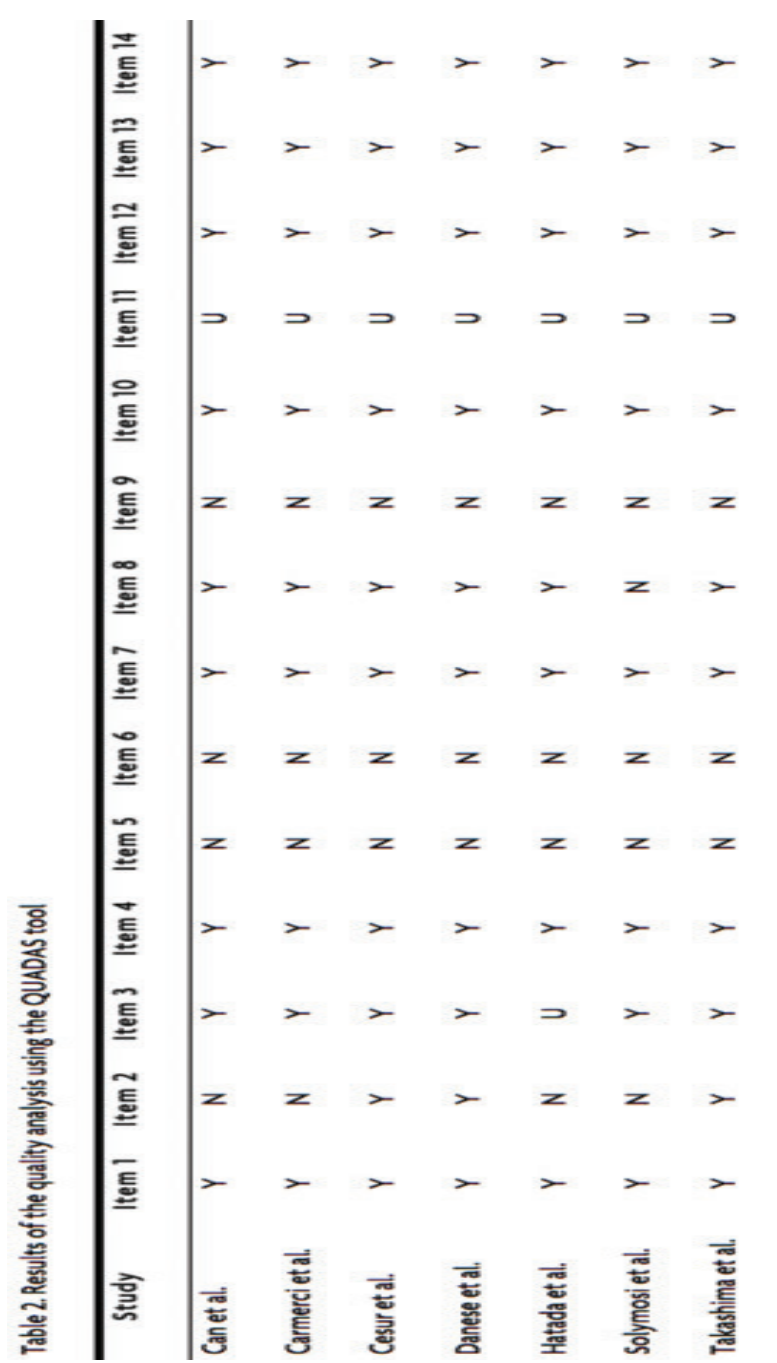


variation across studies attributable to heterogeneity rather than chance.

\section{Results}

The search strategy identified 1934 total unique citations (Figure 1). After a review of the titles and abstracts, 23 studies were selected for a full review. Seven studies met all selection criteria and were included in the meta-analysis. The main reasons for exclusion were evaluation of either US-FNA or PG-FNA, but not both in the same study ${ }^{4,23}$ and missing raw data to allow calculations of sensitivity and specificity. ${ }^{24,25}$ Overall, data on 2305 nodules was included from the studies: 1108 patients underwent PG- FNA and 1197 were tested with USG-FNA.

The baseline characteristics of the included studies are presented in Table 3. All studies, except for Cesur et al. ${ }^{5}$, were retrospective analyses and used two different patient populations for comparison of PG-FNA and
USG-FNA. Cesur et al. ${ }^{5}$ was a comparative prospective study and used the same patient population for both tests. The numbers of participants varied widely between studies. Two studies ${ }^{9,11}$ included more than 350 participants in each group. Two studies included 33-99 participants in each group. ${ }^{10,12}$ Finally, three studies $^{5,7,8}$ included less than 50 participants in each group. No differences were noted between the studies in terms of patient age or gender.

\section{Quality Assessment}

The results of the quality assessment are presented in Table 2. All studies selectively used verification with the reference standard (QUADAS Item 5) and the index test result was verified only in a subset of the sample (Item 6), subsequently being scored as "no." No studies provided an explanation of the surgical technique (Item 9). Studies varied in the extent of the description of the selection criteria (Item 2). No studies stated whether the

\begin{tabular}{|c|c|c|c|c|c|c|c|}
\hline Study & Procedure & $\begin{array}{c}\text { Number of } \\
\text { patients/nodules }\end{array}$ & Benilgn & Malignane & Indet & sinate' & Inadequate ${ }^{2}$ \\
\hline \multirow[t]{2}{*}{$\operatorname{Can} 2008$} & PG-FNEA & 18 & 12 & 2 & & & 3 \\
\hline & US-FNEA & 23 & 11 & 5 & & & 1 \\
\hline \multirow[t]{2}{*}{ Carmerei, 1998} & PG-FNEA & 47 & 13 & 21 & & & 6 \\
\hline & US-FNEA & 17 & 1 & 10 & & & 2 \\
\hline \multirow[t]{2}{*}{ Cesur 06} & PG-FNEA & 26 & 11 & 4 & & & $\mathbf{s}$ \\
\hline & US-FNEA & 26 & 14 & 4 & & & 4 \\
\hline \multirow[t]{2}{*}{ Danese 98} & PG-FNEA & 535 & 307 & 55 & & & 13 \\
\hline & US-FNEA & 540 & 310 & 70 & & & 5 \\
\hline \multirow[t]{2}{*}{ Hatada 98} & PG-FNEA & 94 & 42 & 24 & & & 28 \\
\hline & US-FNEA & 72 & 37 & 23 & & & 12 \\
\hline \multirow[t]{2}{*}{ Solymosi $\infty$} & PG-FNEA & 35.4 & 197 & 120 & & & 37 \\
\hline & US-FNA & 420 & 302 & 78 & & & 40 \\
\hline \multirow[t]{2}{*}{ Takashima 94} & PG-FNEA & 34 & 12 & 22 & & & 0 \\
\hline & US-FNeA & 99 & 32 & 67 & & & 0 \\
\hline \multicolumn{8}{|c|}{ 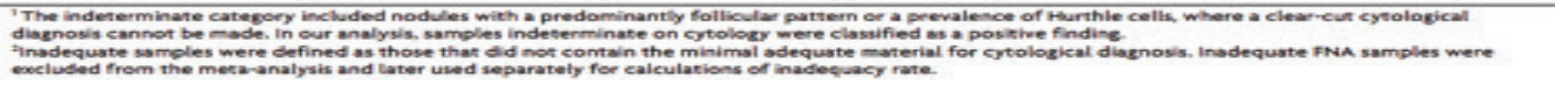 } \\
\hline Study & Technique & Number of Patients & True & ositives & $\begin{array}{l}\text { alse } \\
\text { itives }\end{array}$ & $\begin{array}{c}\text { False } \\
\text { Negatives }\end{array}$ & $\begin{array}{c}\text { True } \\
\text { Negatives }\end{array}$ \\
\hline \multirow[t]{2}{*}{ Can 08} & PG-FNA & 18 & & 2 & 1 & o & 12 \\
\hline & US-FNA & 23 & & 8 & 3 & 0 & 11 \\
\hline \multirow[t]{2}{*}{ Carmeci 98} & PG-FNA & 47 & & 17 & 11 & 2 & 11 \\
\hline & US-FNA & 17 & & 10 & 4 & 0 & 1 \\
\hline \multirow[t]{2}{*}{ Cesur 06} & PG-FNA & 26 & & 4 & 3 & 2 & 9 \\
\hline & USFNA & 26 & & 6 & 2 & 1 & 13 \\
\hline \multirow[t]{2}{*}{ Danese 98} & PGFNA & 535 & & 16 & 136 & 7 & 300 \\
\hline & USFNA & 540 & & 9 & 126 & 3 & 307 \\
\hline \multirow[t]{2}{*}{ Hatada 98} & PGFNA & 94 & & 23 & 1 & 19 & 23 \\
\hline & USFNA & 72 & & 22 & 1 & 11 & 26 \\
\hline \multirow[t]{2}{*}{ Solymosi OO } & PGFNA & 354 & & 19 & 101 & 6 & 191 \\
\hline & USFNA & 420 & & 35 & 102 & 3 & 240 \\
\hline \multirow[t]{2}{*}{ Takashima 94} & PGFNA & 34 & & 21 & 1 & 3 & 9 \\
\hline & USFNA & 99 & & 54 & 3 & 3 & 29 \\
\hline
\end{tabular}


results of the FNA were known during the histological interpretation of the sample. (Item 11)

\section{Results of PG-FNA versus USG-FNA}

The diagnostic accuracy values of the included studies are presented in Table 4. For USG-FNA, the pooled sensitivity and specificity, using the random effects model (with 95\% confidence intervals), were 0.906 $(0.816,0.996)$ and $0.769(0.686,0.853)$, respectively (Figures 2 and 3 ). The sensitivity and specificity values for PG-FNA using the random effects model (with $95 \%$ confidence intervals) were 0.794 (0. 659, 0.928) and $0.727(0.644,0.810)$ (Figures 4 and 5). These results were also plotted on a receiver operating characteristic (ROC) curve (Figure 6) demonstrating the corresponding sensitivity and specificity values along with the $95 \%$ confidence intervals.
The rates of inadequacy varied between the two techniques. In PG-FNA, the mean rate of inadequate samples was $14.7 \%$. For USG-FNA, the mean rate of inadequate samples was $8.4 \%$.

\section{Discussion}

A number of studies over the last two decades have investigated the sensitivity and specificity of PG-FNA and USG-FNA. The sensitivity and specificity of PG-FNA has been reported to be anywhere between $57 \%-98 \%$ and $72 \%-100 \%$, respectively. ${ }^{13,26-29}$ The sensitivity and specificity of USG-FNA is reported to be between $66 \%-100 \%$ and $70 \%-96 \%{ }^{8}$

This meta-analysis showed that the pooled sensitivity of USG-FNA was found to be higher than PG-FNA (0.906 and 0.769, respectively). The pooled specificity

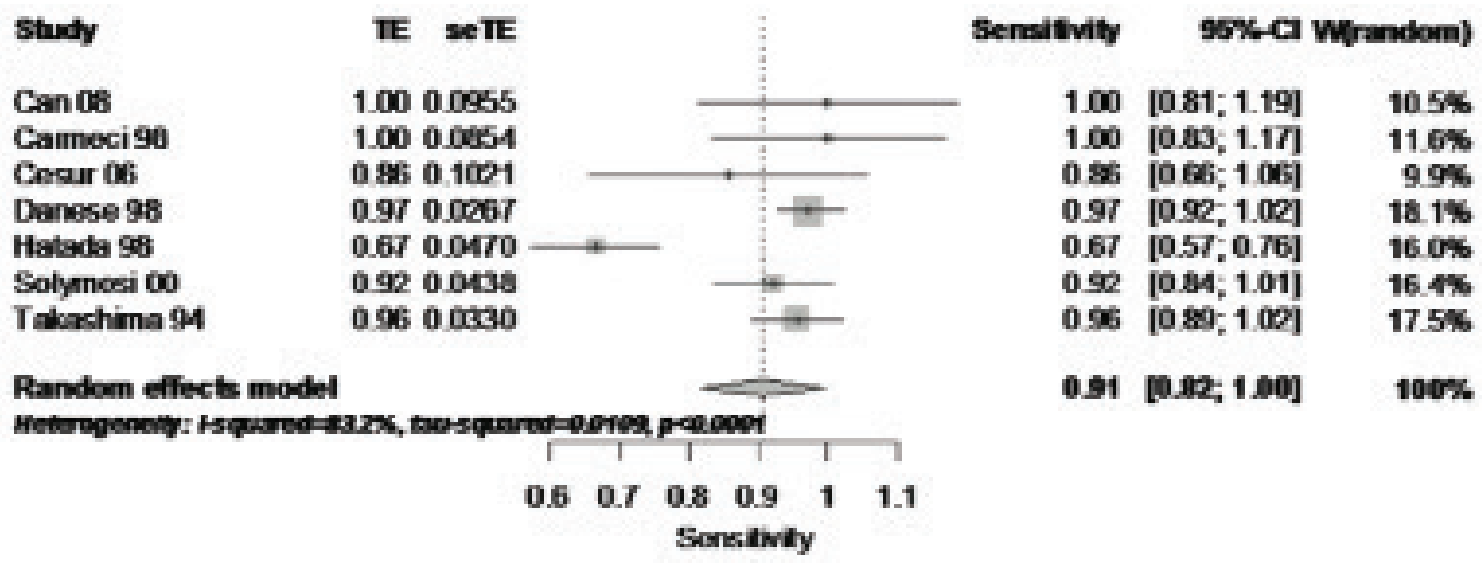

Figure 2. A Forest plot summarizing the meta analysis of sensitivity of USG-FNA.

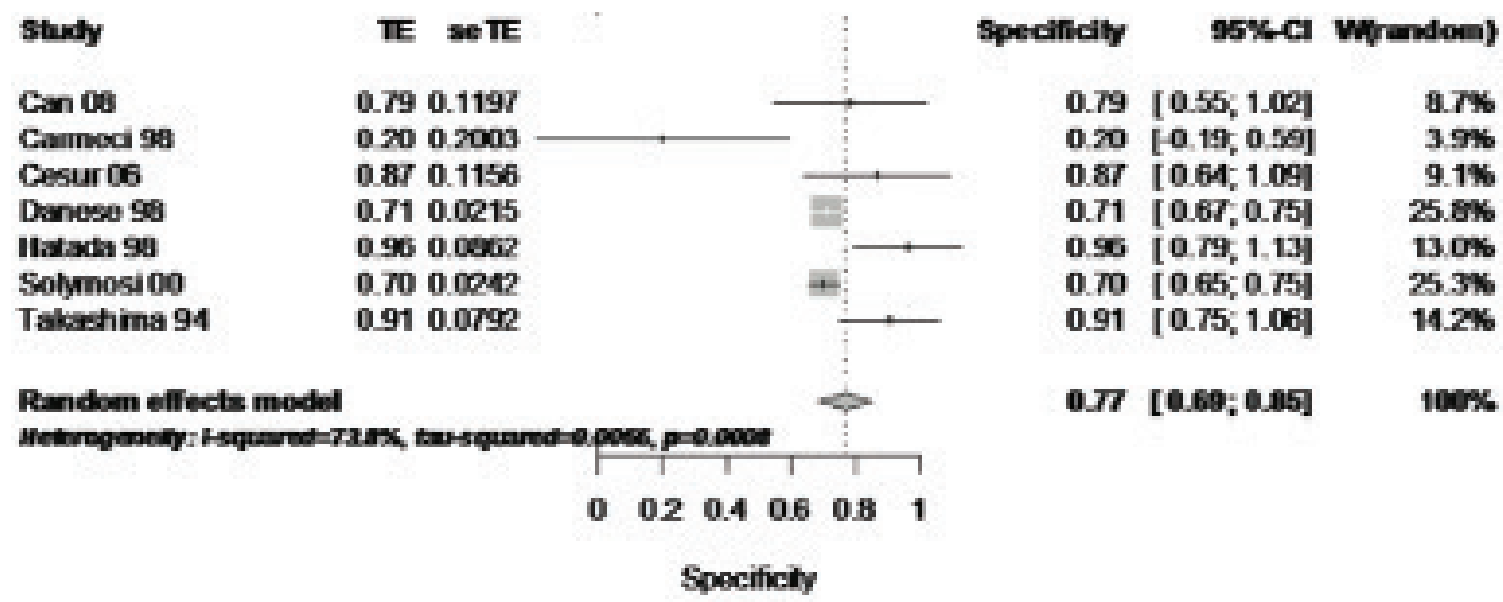

Figure 3. A Forest plot summarizing the meta analysis of specificity of USG-FNA. 


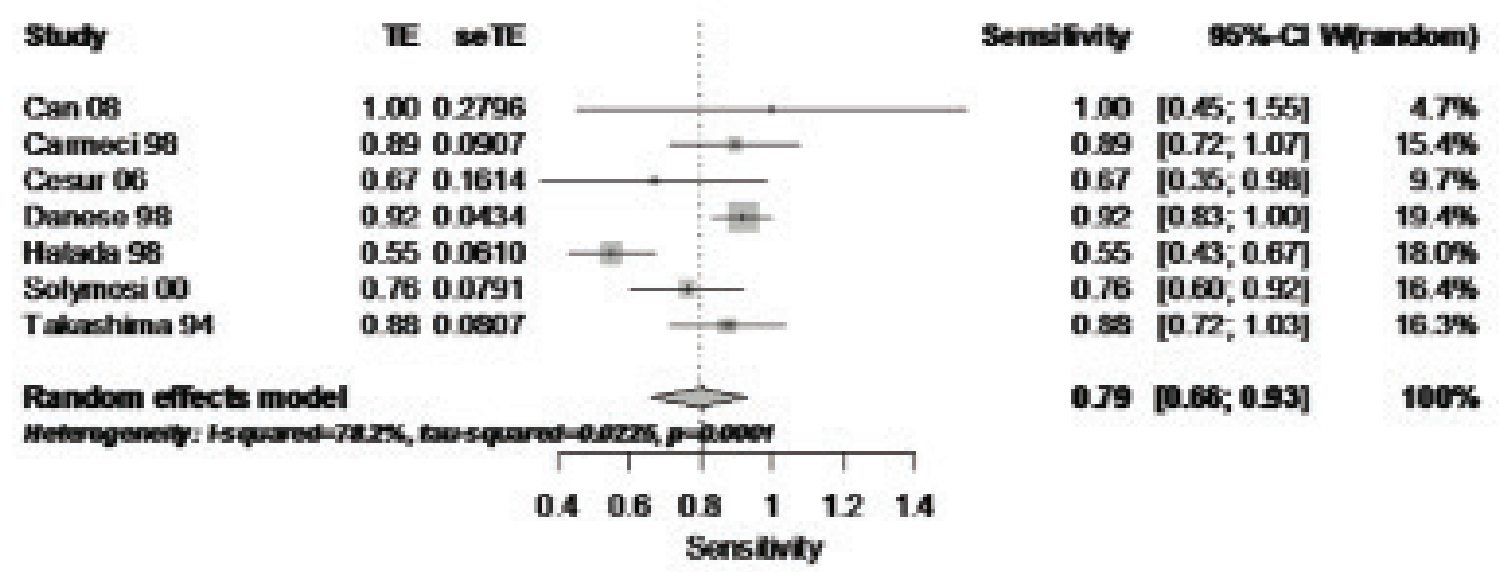

Figure 4. A Forest plot summarizing the meta analysis of the sensitivity of PG-FNA.

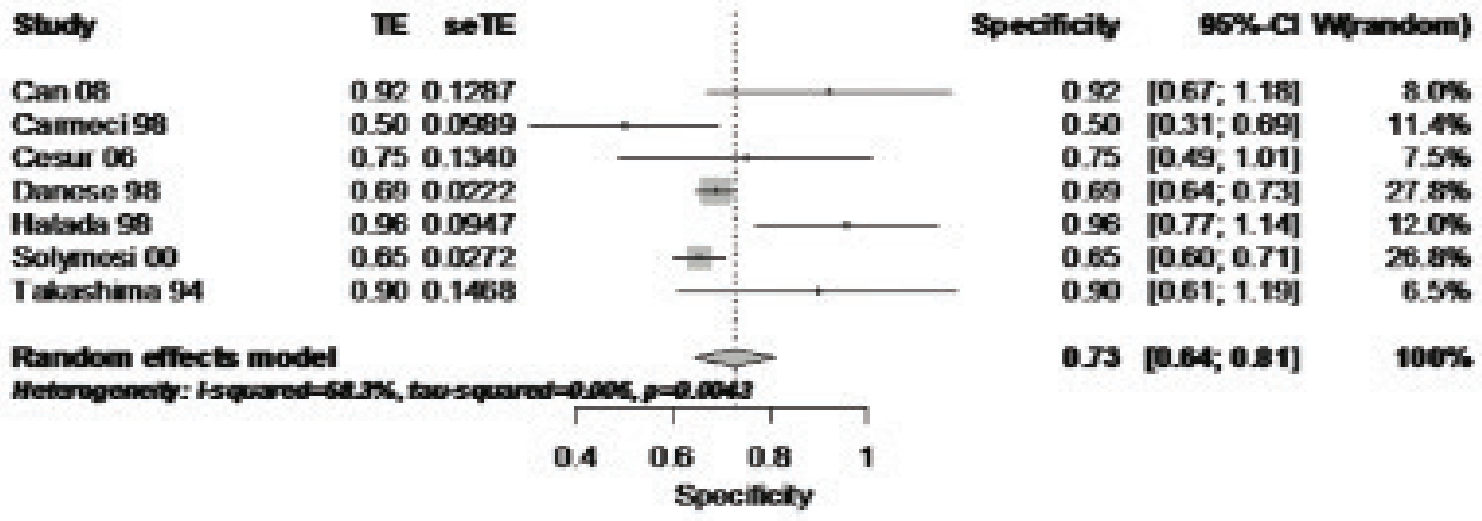

Figure 5. A Forest plot summarizing the meta analysis of the specificity of PG-FNA.

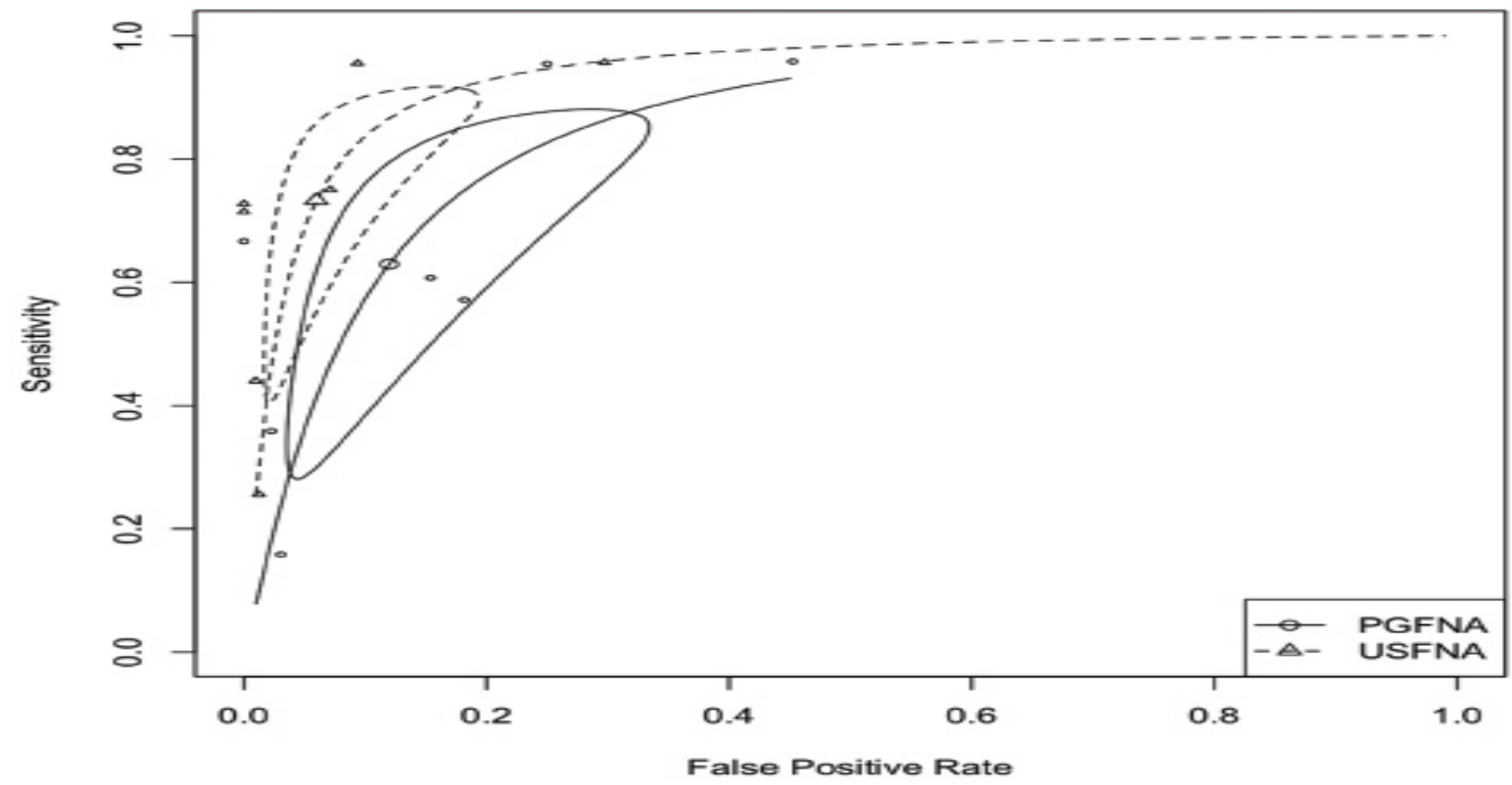

Figure 6. Summary ROC curve showing the comparison of USG-FNA and PG-FNA. 
of USG-FNA was also found to be slightly higher than PG-FNA (0.769 and 0.727, respectively). The summary ROC curves and the $95 \%$ confidence regions for both PG-FNA and USG-FNA pooled study estimates are well above the line of no discrimination. The summary ROC plot shows the curve for USG-FNA to consistently lie above the curve for PG-FNA, providing evidence of superior accuracy of USG-FNA. In addition, the USG-FNA pooled study estimate is superior to the PG-FNA pooled study estimate, albeit with some overlap in their $95 \%$ confidence regions. In comparison to previous studies ${ }^{8,13,26-29}$, the diagnostic accuracy values that we found in our meta-analysis is at the upper range of the estimates for both techniques. Reasons for variability between studies may include differences in the operator's experience with the technique, as well as differences in the criteria used for histological interpretation.

Current published guidelines by the ATA, NCI, BTA, and AACE/AME/ETA are in agreement that USG-FNA should be used for nodules that are non-palpable, difficult to palpate, or partially cystic nodules. The inconsistency in the recommendations pertains to the use of USG-FNA for palpable nodules. We found that studies differed with respect to the type of nodules allocated to PG-FNA and USG-FNA. Three of the studies ${ }^{7,11,12}$ preferentially allocated nodules that were non-palpable, difficult to palpate, or nodules that failed PG-FNA to cytology by USG-FNA. The remaining four studies ${ }^{5,8-10}$ did not actively triage patients to a specific technique. It is possible that by allocating more "challenging" nodules to USG-FNA, the sensitivity and specificity of USG-FNA may be underestimated or alternatively, the diagnostic accuracy of PG-FNA improved. This is a potential source of bias.

The cost of a diagnostic technique is an important factor that needs to be taken into consideration relative to the potential benefits that the technique offers. PG-FNA is a simple technique that can be easily implemented in the office setting, and most clinicians are familiar with it. USG-FNA requires more specialized equipment, requires additional training, and may be more costly. Indeed, several studies have shown that USG-FNA is less cost effective than PG-FNA., ${ }^{5,30}$ On the other hand, Can et $\mathrm{al}^{31}$ found that although USG-FNA is more expensive than PG-FNA, the increased diagnostic accuracy and decreased inadequacy rate that USG-FNA offers make it into a more cost-effective strategy. The rates of inadequacy found in our meta-analysis are comparable to those reported in the studies that were reviewed and confirm that USG-FNA, on average, has a lower rate of inadequacy (14.7\% versus $8.4 \%)$.
Our meta-analysis has a number of limitations. In most of the included studies, the same patients did not undergo both PG-FNA and USG-FNA, which would allow a direct comparison. Cesur et $a .^{5}$ was the only study where the entire patient population underwent a PG-FNA that was followed immediately by an USG-FNA. Having the patients undergo both diagnostic techniques reduces the possibility of a selection bias. An additional limitation is that in some of the studies, more than one person performed the aspirations. This leaves room for heterogeneity in the results due to operator experience. Furthermore, not all studies used the same number of passes in the thyroid nodule. It is possible that the number of passes may affect the diagnostic accuracy of the technique, leading to inconsistency across the studies. A final limitation is that the included studies varied in their classification of indeterminate nodules. In our analysis, nodules that were deemed to be indeterminate on cytology were classified as a positive finding. Notably, the risk of categorizing the indeterminate results as positive is increasing the false positive rate of cytological diagnosis. However, since this adjustment is applied across all studies, this increase is uniform and was not expected to bias the relative diagnostic accuracy of each technique. An additional discrepancy between the studies was the classification of inadequate samples. Some of the studies included the inadequate samples in their calculations of sensitivity and specificity ${ }^{8}$, while other studies excluded inadequate samples entirely from their calculations. ${ }^{9}$ Only diagnostic and indeterminate FNA samples were included in our meta-analyses. Inadequate FNA samples were excluded and later used separately for calculations of the average inadequacy rate.

\section{Conclusions}

The purpose of this meta-analysis was to compare USG-FNA with PG-FNA in order to determine which diagnostic technique is superior in terms of sensitivity, specificity, and inadequacy rates. USG-FNA was found to have higher sensitivity than PG-FNA in the diagnosis of thyroid nodules. USG-FNA was also found to have a slightly higher specificity than PG-FNA. Inadequacy rates were, on average, lower with USG-FNA than with PG-FNA. These findings suggest that US-FNA is the more accurate technique. Therefore, there appears to be an advantage to the use of USG-FNA over PG-FNA of thyroid nodules.

\section{Acknowledgements}

We thank the Dalhousie University librarian Tim Ruggles and Capital Health librarian Penny Logan for helping carry out the literature searches. 


\section{References}

1. Hegedus L. Clinical practice. The thyroid nodule. N Engl J Med 2004;351:1764-1771.

2. Tan GH, Gharib H. Thyroid incidentalomas: management approaches to nonpalpable nodules discovered incidentally on thyroid imaging. Ann Intern Med 1997;126:226-231.

3. Mazzaferri EL. Management of a solitary thyroid nodule. N Engl J Med 1993;328:553-559.

4. Schwartz J, How J, Lega I, Cote J, Gologan O, Rivera JA, et al. Ultrasound-guided fine-needle aspiration thyroid biopsies in the otolaryngology clinic. J Otolaryngol Head Neck Surg 2010;39:356360.

5. Cesur M, Corapcioglu D, Bulut S, Gursoy A, Yilmaz AE, Erdogan $\mathrm{N}$, et al. Comparison of palpation-guided fine-needle aspiration biopsy to ultrasound-guided fine-needle aspiration biopsy in the evaluation of thyroid nodules. Thyroid 2006;16:555-561.

6. Cooper DS, Doherty GM, Haugen BR, Kloos RT, Lee SL, Mandel $\mathrm{SJ}$, et al. American Thyroid Association Guidelines. Management guidelines for patients with thyroid nodules and differentiated thyroid cancer. Thyroid 2006;16:109-142.

7. Carmeci C, Jeffrey RB, McDougall IR, Nowels KW, Weigel RJ. Ultrasound-guided fine-needle aspiration biopsy of thyroid masses. Thyroid 1998;8:283-289.

8. Can AS, Peker K. Comparison of palpation-versus ultrasoundguided fine-needle aspiration biopsies in the evaluation of thyroid nodules. BMC Res Notes 2008;1:12.

9. Danese D, Sciacchitano S, Farsetti A, Andreoli M, Pontecorvi A. Diagnostic accuracy of conventional versus sonography-guided fine-needle aspiration biopsy of thyroid nodules. Thyroid 1998;8:1521.

10. Hatada T, Okada K, Ishii H, Ichii S, Utsunomiya J. Evaluation of ultrasound-guided fine-needle aspiration biopsy for thyroid nodules. Am J Surg 1998;175:133-136.

11. Solymosi T, Toth GL, Bodo M. Diagnostic accuracy of fine needle aspiration cytology of the thyroid: impact of ultrasonography and ultrasonographically guided aspiration. Acta Cytol 2001;45:669674

12. Takashima S, Fukuda H, Kobayashi T. Thyroid nodules: clinical effect of ultrasound-guided fine-needle aspiration biopsy. J Clin Ultrasound 1994:22:535-542.

13. Gharib H, Goellner JR. Fine-needle aspiration biopsy of thyroid nodules. Endocr Pract 1995;1:410-417.

14. Redman R, Zalaznick H, Mazzaferri EL, Massoll NA. The impact of assessing specimen adequacy and number of needle passes for fineneedle aspiration biopsy of thyroid nodules. Thyroid 2006;16:5560.

15. Seiberling KA, Dutra JC, Gunn J. Ultrasound-guided fine needle aspiration biopsy of thyroid nodules performed in the office. Laryngoscope 2008;118:228-231.

16. Cooper DS, Doherty GM, Haugen BR, Kloos RT, Lee SL, Mandel SJ, et al. Revised American Thyroid Association management guidelines for patients with thyroid nodules and differentiated thyroid cancer. Thyroid 2009;19:1167-1214.

17. Baloch ZW, Cibas ES, Clark DP, Layfield LJ, Ljung BM, Pitman MB, et al. The National Cancer Institute. Thyroid fine needle aspiration state of the science conference: a summation. Cytojournal 2008;5:6.

18. Guidelines for the management of thyroid cancer, 2nd Edition British Thyroid Association and Royal College of Physicians. 2007 〈www.british-thyroid-association.org〉.

19. Gharib H, Papini E, Valcavi R, Baskin HJ, Crescenzi A, Dottorini $\mathrm{ME}$, et al. Nodules AATFoT American Association of Clinical Endocrinologists and Associazione Medici Endocrinologi medical guidelines for clinical practice for the diagnosis and management of thyroid nodules. Endocr Pract 2006;12:63-102.

20. Whiting P, Rutjes AW, Reitsma JB, Bossuyt PM, Kleijnen J. The development of QUADAS: a tool for the quality assessment of studies of diagnostic accuracy included in systematic reviews. BMC Med Res Methodol 2003;3:25.

21. Schwarzer G. Meta-Analysis with R. R package version 2. 2012;1-4. .

22. Team RC. R: A language and environment for statistical computing. R Foundation for Statistical Computing, Vienna, Austria. 2012.

23. Harvey JN, Parker D, De P, Shrimali RK, Otter M. Sonographically guided core biopsy in the assessment of thyroid nodules. J Clin Ultrasound 2005;33:57-62.

24. Izquierdo R, Arekat MR, Knudson PE, Kartun KF, Khurana K, Kort K, et al. Comparison of palpation-guided versus ultrasound-guided fine-needle aspiration biopsies of thyroid nodules in an outpatient endocrinology practice. Endocr Pract 2006;12:609-614.

25. Mittendorf EA, Tamarkin SW, McHenry CR. The results of ultrasound-guided fine-needle aspiration biopsy for evaluation of nodular thyroid disease. Surgery 2002;132:648-653; discussion 653644

26. Gharib H. Fine-needle aspiration biopsy of thyroid nodules: advantages, limitations, and effect. Mayo Clin Proc 1994;69:44-49.

27. Gardiner GW, de Souza FM, Carydis B, Seemann C. Fine-needle aspiration biopsy of the thyroid gland: results of a five-year experience and discussion of its clinical limitations. J Otolaryngol 1986;15:161-165.

28. Castro MR, Gharib H. Thyroid fine-needle aspiration biopsy: progress, practice, and pitfalls. Endocr Pract 2003;9:128-136.

29. Jeffrey PB, Miller TR. Fine-needle aspiration cytology of the thyroid. Pathology (Phila) 1996;4:319-335.

30. Khalid AN, Quraishi SA, Hollenbeak CS, Stack BC, Jr. Fine-needle aspiration biopsy versus ultrasound-guided fine-needle aspiration biopsy: cost-effectiveness as a frontline diagnostic modality for solitary thyroid nodules. Head Neck 2008;30:1035-1039.

31. Can AS. Cost-effectiveness comparison between palpation- and ultrasound-guided thyroid fine-needle aspiration biopsies. BMC Endocr Disord 2009;9:1. 